\title{
Adermatoglyphia: Barriers to Biometric Identification and the Need for $a$ Standardized Alternative
}

\author{
Nuraiz Sarfraz
}

1.

Corresponding author: Nuraiz Sarfraz, sarfraznuraiz@gmail.com

\section{Abstract}

Arguably, fingerprinting is the single most widely utilized method for individual identification and authentication (I\&A). Dermatoglyphics form a vital portion of mass data collection, biometric scrutiny, and verification. Adermatoglyphia, or simply, loss of fingerprints attributed to a medical cause, represents a taxing situation for such biometric scrutiny systems requiring a fingerprint scan as a mandatory phase in I\&A procedure. The scenario can be extremely debilitating for the adermatoglyphia patients, especially when the condition is permanent or irreversible. This article reviews different causes of adermatoglyphia, the challenge it poses to biometric identification, and the potential substitute modalities for fingerprinting technology. These modalities can function as a backup program for biometric surveillance in both medical and non-medical settings under circumstances when the fingerprinting method fails to comply.

Categories: Dermatology, Quality Improvement, Healthcare Technology

Keywords: finger printing, adermatoglyphia, loss of fingerprints, biometrics, identification and authentication

\section{Introduction And Background}

Dermatoglyphics (from the roots "derma" for skin and "glyphos" for carvings) is the study of various integumentary ridge patterns that form on fingertips, toes, palms of the hands, and soles of the feet. Fingerprinting describes the technical aspects of recording the skin ridge pattern present on fingertips, establishing one of the key components of human identification. More than a century ago, Sir Francis Galton discovered that these ridge patterns are astoundingly constant throughout the lifespan of an individual [1]. Later, the term “dermatoglyphics” was introduced by Dr. Harold Cummins in 1936 [2].

Received 01/30/2019

Review began 02/01/2019 Review ended 02/04/2019 Published 02/08/2019

\section{(c) Copyright 2019}

Sarfraz. This is an open access article distributed under the terms of the Creative Commons Attribution License CC-BY 3.0., which permits unrestricted use, distribution, and reproduction in any medium, provided the original author and source are credited.
Fingerprinting is the most commonly utilized method for human identification and authentication (I\&A) [3]. It is an integral component of a personal profile and biodata. Most government and private sectors seeking or involving personal biometric information require individuals to be fingerprinted to complete routine biometric record and documentation. Not only does fingerprinting concern the conventional domains of clinical medicine, forensic science, anthropometry, criminology, customs, and security agencies [3], its applicability has been incorporated into every so-called formal "security screen". The spectrum of its utility ranges from gaining access to sensitive computerized documents and handling transactions to checking-in for daily office work and unlocking mobile phones and electronic devices [4-5].

Adermatoglyphia is clinically defined as the congenital or an acquired loss of this epidermal ridge pattern [6]. It can be limited to a few digits or all fingers and can also refer to the absence 


\section{Cureus}

of the ridge patterns formed on the plantar aspects of the feet. Furthermore, adermatoglyphia can refer to a partial loss of the ridges (i.e., ridges are unnoticeable on general evaluation but detectable on deep inspection or under a magnifying lamp) or a complete absence (depicting total effacement) of epidermal ridges. Such scenarios present time-consuming challenges not only for the authorities but also for the concerned individual, in completing verification procedures (Figures 1, 2). Face recognition and fingerprinting are the primary modes of biometric I\&A worldwide. Any technical problem or error hampering this series of verification steps can cause the entire verification process to come to a halt [7]. This article discusses the obstacles faced by patients suffering from adermatoglyphia undergoing a mandatory biometric fingerprinting procedure. Additionally, this review highlights the necessity of a standardized, globally acceptable criterion that can act as a biometric substitute protocol. Such a biometric substitute system can function as a backup option under circumstances when the conventional fingerprinting verification fails or is not applicable (e.g., patients suffering from adermatoglyphia or amputated limbs).

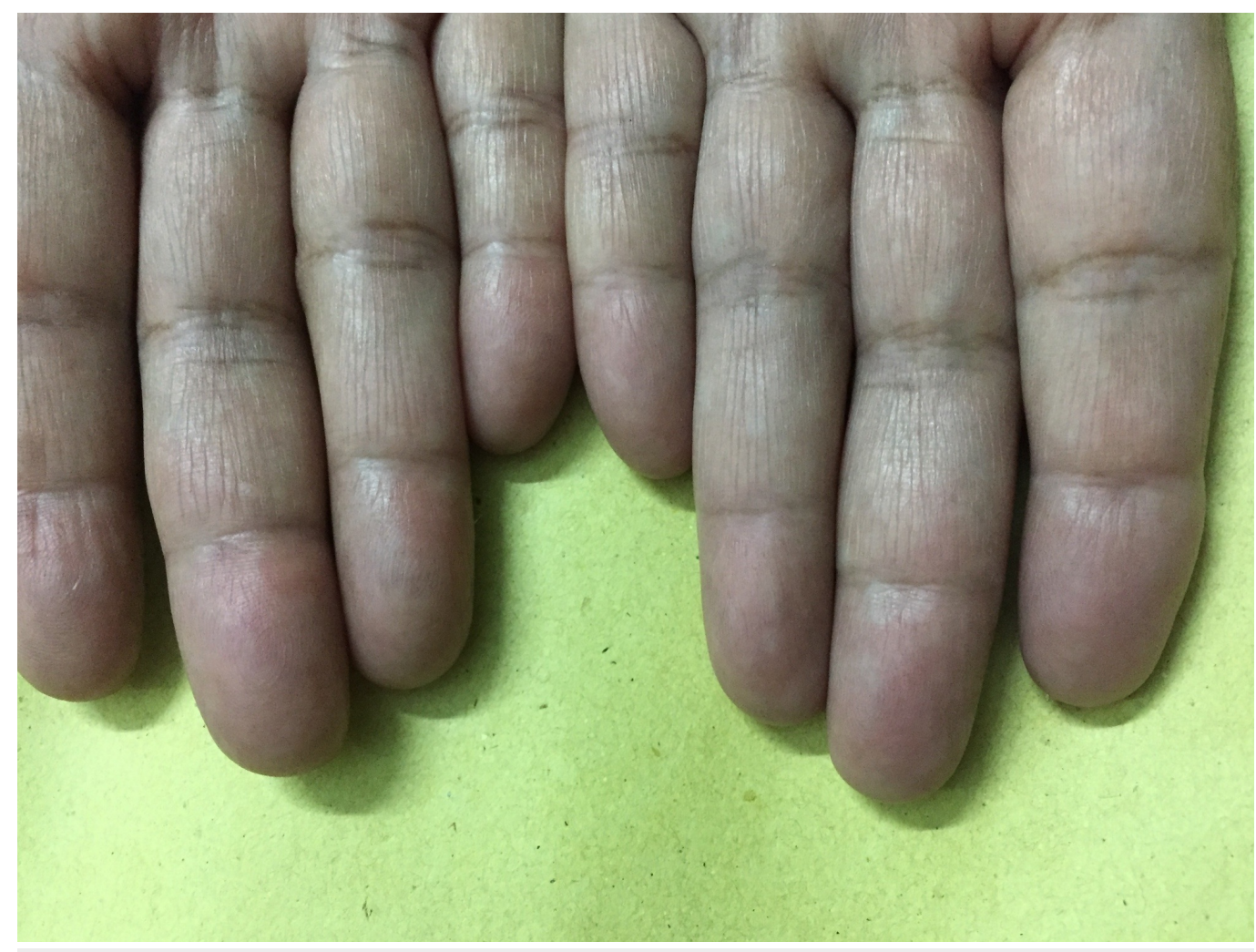

\section{FIGURE 1: Acquired idiopathic adermatoglyphia in a 59-year- old female patient showing fingers of both hands}

This woman visited the dermatology department in July 2016 for medical evaluation. She realized the loss of her fingerprints when she was unable to renew her national identity card, requiring her to be ten-printed (i.e., all fingers and thumbs of both hands were scanned/printed). Except for hypertension well-controlled with medication, her past medical history, physical exam, and laboratory reports failed to identify any probable cause of her findings. A detailed physical exam revealed marked effacement of ridges, involving fingers of both hands (Image courtesy of Dermatology Department, Mayo hospital, Lahore). 


\section{Cureus}

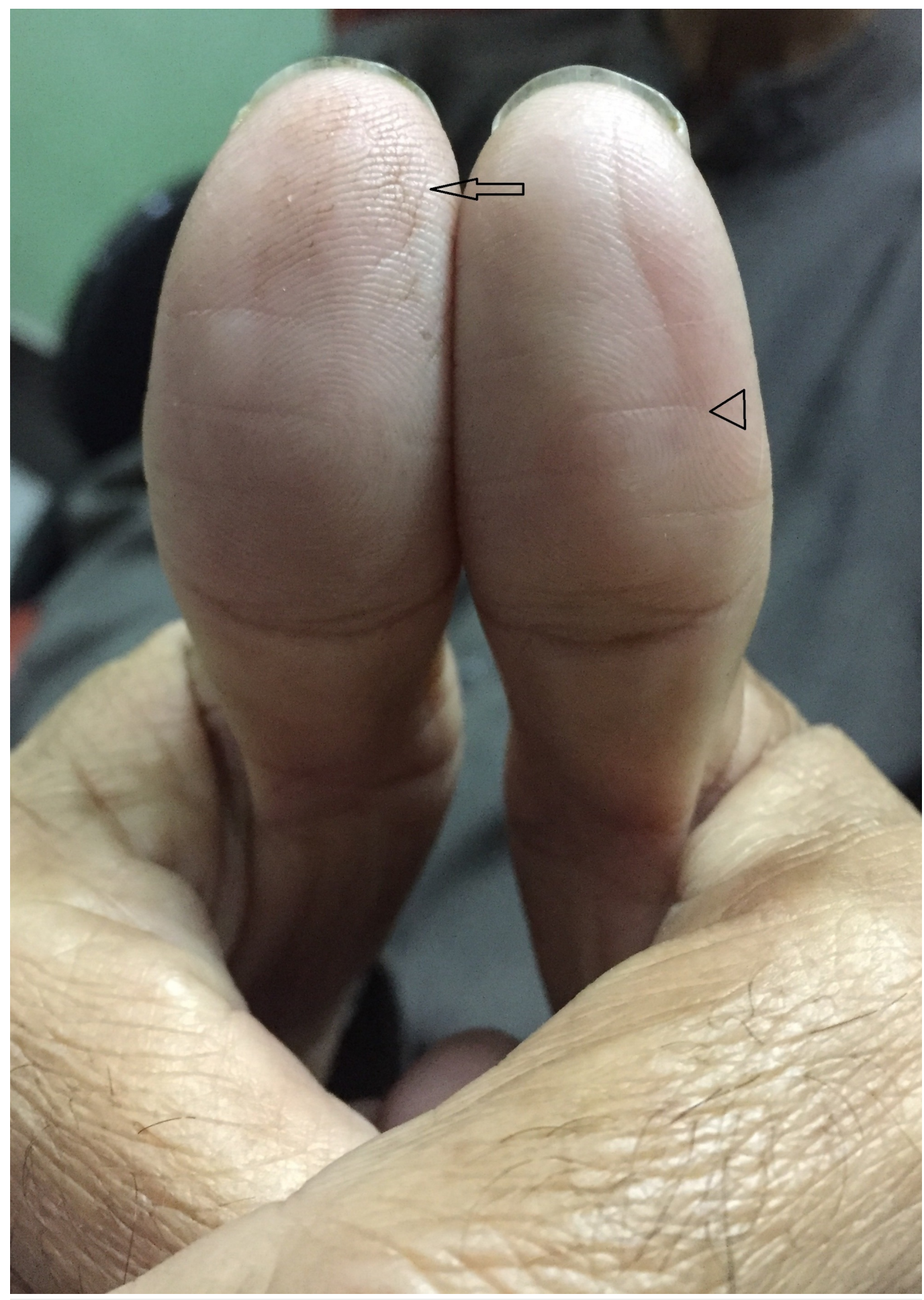

FIGURE 2: Geriatric atrophy of epidermal ridges in a 66-yearold male patient showing thumbs of both hands

This patient presented in November 2017 to obtain a medical certificate to access his bank account. The bank accounts were being biometrically verified, and repeated attempts to scan his fingertips failed to record any discernible pattern. Note the atrophy of epidermal ridges around the center of digital pulp with fissuring "black arrow" along with the formation of transverse creases "arrowhead" (Image courtesy of Dermatology Department, Mayo hospital, Lahore). 


\section{Cureus}

\section{Review}

Fingerprints are important dermatological landmarks with substantial applications in medicine, forensics, anthropology, and security. The epidermal ridges usually develop around 10 to 17 weeks post-fertilization, and their formation is influenced by genetic and environmental components [6]. The development affected by multiple genes during embryogenesis results in the formation of a perpetually unique pattern persisting throughout the lifespan of an individual [6]. However, there are certain congenital and acquired conditions that can affect the integrity of dermatoglyphics (Tables 1-3).

\begin{tabular}{|c|c|c|}
\hline Diseases & Genetics & Dermatoglyphic Features \\
\hline Down syndrome & Trisomy 21 & $\begin{array}{l}\text { Simian line, fewer ridges along digital midline, distinct ATD angle, predominance of } \\
\text { ulnar loops }\end{array}$ \\
\hline Turner syndrome & $45, \times 0$ & Predominance of whorls depending on the type of chromosomal abnormality \\
\hline $\begin{array}{l}\text { Klinefelter } \\
\text { syndrome }\end{array}$ & 47, XXY & $\begin{array}{l}\text { Excessive arches on digit 1, more ulnar loops on digit 2, fewer whorls, lower finger } \\
\text { ridges }\end{array}$ \\
\hline $\begin{array}{l}\text { Edwards' } \\
\text { syndrome }\end{array}$ & Trisomy 18 & 6 to 10 arches on fingertips and Simian crease in $30 \%$ of cases \\
\hline Patau syndrome & Trisomy 13 & Excess arches on fingertips, polydactyly and Simian line in $60 \%$ cases \\
\hline $\begin{array}{l}\text { Noonan } \\
\text { syndrome }\end{array}$ & $\begin{array}{l}\text { Multiple } \\
\text { genes/AD }\end{array}$ & Increased whorls on fingertips and axial tri-radius, Simian line in certain cases \\
\hline
\end{tabular}

\section{TABLE 1: Genetic disorders with abnormal dermatoglyphics}

$A D$, autosomal dominant; ATD angle, axial tri-radii angle [3] 


\section{Cureus}

\begin{tabular}{|c|c|c|c|}
\hline Categories & Trait & Features & Associations \\
\hline Ridge aplasia & $A D$ & $\begin{array}{l}\text { Absence over entire palmoplantar } \\
\text { surfaces; muted SMARCAD1 helicase } \\
\text { isoforms in certain cases }\end{array}$ & $\begin{array}{l}\text { Congenital facial milia, acral blistering, digital } \\
\text { contractures and nail abnormalities in rare } \\
\text { Basan Syndrome [8] }\end{array}$ \\
\hline $\begin{array}{l}\text { Ridge } \\
\text { hypoplasia }\end{array}$ & $A D$ & Not absents but less conspicuous & Excess of white lines on the prints \\
\hline $\begin{array}{l}\text { Ridge } \\
\text { dissociation }\end{array}$ & AD/sporadic & $\begin{array}{l}\text { Ridge dots, enclosures, bifurcations and } \\
\text { crosses, may be mistaken as scarring }\end{array}$ & $\begin{array}{l}\text { Found in some patients with schizophrenia, } \\
\text { Down syndrome, epilepsy, and albinism. }\end{array}$ \\
\hline $\begin{array}{l}\text { Ridges-off-the- } \\
\text { end }\end{array}$ & $A D$ & $\begin{array}{l}\text { Instead of running transversely, ridges } \\
\text { run vertically off the fingertips }\end{array}$ & NA \\
\hline $\begin{array}{l}\text { Ridges-off-the- } \\
\text { end with } \\
\text { dissociation }\end{array}$ & NA & $\begin{array}{l}\text { A combination of ridge dissociation and } \\
\text { ridges running vertically off the end [9]. }\end{array}$ & NA \\
\hline
\end{tabular}

\section{TABLE 2: Congenitally abnormal dermatoglyphics with relative physical and clinical associations}

$A D$, autosomal dominant inheritance; NA, not applicable [3,6-9]

\section{Dermatological Causes}

Dermatitis

1. Contact dermatitis

2. Allergic dermatitis

3. Atopic eczema

4. Dyshidrotic eczema

5. Miscellaneous dermatitis affecting volar surfaces Infectious

\section{Scabies}

2. Herpetic Whitlow

3. Pyoderma/Impetigo

4. Pitted keratolysis

5. Palmar warts

6. Lepromatous leprosy

7. Syphilitic rash

\section{Non-dermatological Causes}

Accidental

1. Trauma

2. Burns

3. Amputation

4. Caustic abrasion

5. Denervation injury

Drug-related

1. Potent topical steroids

2. Capecitabine chemotherapy

Medical disorders

1. Metabolic/medical disorders causing neuropathy

2. Celiac disease 


\section{Cureus}

8. Coxsackievirus A rash

3. Malnutrition/Nutritional deficiencies

9. Scarlet fever/SSS

Miscellaneous

1. Occupational micro-abrasions

Drug-induced Rash

2. Prolonged liquid immersion

1. Erythema multiforme

2. Steven Johnson syndrome

3. Idiopathic

3. Toxic epidermal necrolysis

4. latrogenic/Dermatitis artefacta

4. Serum sickness/GVHD

5. Normal aging

Immune-mediated

1. Cutaneous LE

2. Epidermolysis bullosa

3. Pemphigus vulgaris

4. Systemic sclerosis

5. Psoriasis

6. Kawasaki's disease

7. Dermatitis herpetiformis

8. Keratoderma blennorrhagica

Miscellaneous

1. Gangrene

2. Lichen

3. Primary Hyperhidrosis

4. Keratoderma

5. Xanthoma striatum palmare

6. Acanthosis nigricans

7. Acrodermatitis enteropathica

8. Dermatoses involving volar surface of fingers

\section{TABLE 3: Transient and permanent causes of acquired adermatoglyphia}

GVHD, graft versus host disease; SSS, scalded skin syndrome; LE, lupus erythematosus [3,7,10-11] 


\section{Epidemiology of adermatoglyphia}

An extensive literature review to evaluate the prevalence of fingerprint loss among the general population due to congenital and acquired disease yielded a paucity of data. In a national survey conducted in a Lebanese population in 2013, the incidence of absent fingerprints was $0.18 \%$, predominantly affecting those in the geriatric age group (aged 65 years or older) and women more than men [7]. The incidence of loss of fingerprints was $0.3 \%$ for those 24 years or younger, $2.8 \%$ for those aged 25 to 64 years, and $8.5 \%$ for those aged 65 years or older. For cases where absent fingerprints were attributed to dermatological causes, the number of female patients was 3.75 times greater than the number of male patients [7]. Most of these female patients were housewives.

\section{Congenital causes of adermatoglyphia}

Some genetic disorders can indirectly predispose a person to abnormal fingerprint configurations (Table 1 illustrates a few such causes) [3]. Furthermore, conditions that directly affect the gross morphology of the fingers (e.g., polydactyly, syndactyly, brachydactyly, and ectrodactyly) can also skew the conventional parameters of biometric fingerprinting procedure [7]. Congenitally abnormal dermatoglyphics can be categorized into five basic domains (Table 2). Such phenotypic variants are rarely encountered in the general population [3,6-9].

\section{Acquired causes of adermatoglyphia}

Acquired causes substantially eclipse the congenital causes of abnormal dermatoglyphics. Indeed, the loss of epidermal ridges is not an uncommon observation, especially in the elderly population (i.e., those aged 65 years or above). Interestingly, one study found adermatoglyphia to be more common in women than men [7]. Acquired adermatoglyphia can be further classified by dermatological and non-dermatological causes (Table 3). Trauma, amputation, and burns are among the more commonly encountered, accidental, non-dermatological etiologies. In the Lebanese national survey by Haber et al., dermatological causes accounted for $52.9 \%$ of all cases of adermatoglyphia, with dermatitis contributing to the majority of these cases (61\%) [7].

Certain drugs like potent corticosteroids can cause epidermal ridge atrophy [10], and in recent years, capecitabine-induced adermatoglyphia has resulted in immigration delays at airports and travel warnings for patients undergoing capecitabine chemotherapy [11]. The list of acquired causes of adermatoglyphia is quite extensive (Table 3), highlighting the gravity of this issue in the general population $[3,7,10-11]$.

\section{Methods of human identification and authentication}

An in-depth analysis of medical literature was conducted involving MEDLINE and PubMed medical databases, including ResearchGate and using the following terms: adermatoglyphia, dermatoglyphics, loss of fingerprints, and biometrics both individually and in combination. Surprisingly, no articles were found in the scientific literature discussing specific guidelines or a protocol for adermatoglyphia patients undergoing a mandatory fingerprint verification. The main objective of this article was to signify the necessity of a second-line substitute I\&A system, especially for patients suffering from irreversible adermatoglyphia. Issuing a medical certificate is medico-legally imperative but only provides a temporary solution, as the validity and the authenticity of such certificates might not be acceptable by other organizations.

Furthermore, different set-ups demand different types of biometric verification, often involving mandatory, multi-modal biometric functions [12-13] operating without a backup plan.

Additionally, some corporations require only thumb-printing for monitoring office attendances or bank account verification. Other agencies granting citizenship, driver's licenses, passports, and immigration papers require a more stringent policy, requiring individuals to be ten-printed. 


\section{Cureus}

Therefore, a substitute I\&A system is recommended that can function globally as a default program for patients suffering from irreversible adermatoglyphia.

\section{Biometrics}

Over the past few decades, many advancements have been made in biometric technology with the introduction of new measurable biological traits as potential biometric targets. Table 4 presents a concise review of the indispensable characteristics required for a biometric indicator. While many of these biological traits fulfill the necessary characteristics (Table 4) required to qualify as a biometric indicator, feasibility becomes the most important factor based upon efficacy, social acceptability, the technical complexity of systems, ease of applicability, and cost-effectiveness. Consequently, there is no single biometric indicator that ideally achieves all these parameters. Therefore, hybrid or complex multi-modal biometric systems are used to enhance the accuracy and efficacy of I\&A [12-13].

\section{Characteristic}

Generality

Uniqueness

Stability

Quantifiable

\section{Definition}

Universally present in all individuals

No individuals share the same configuration

Unchanging throughout the lifespan

Measurable for comparison

\section{TABLE 4: Essential qualities of a biometric indicator}

Biometric traits can be divided into physiological subtypes (e.g., fingerprinting, face recognition, hand geometry, and iris and retinal scan), and behavioral subtypes (e.g., signatures, keystroke, and voice and gait patterns; Figure 3) [14-16].

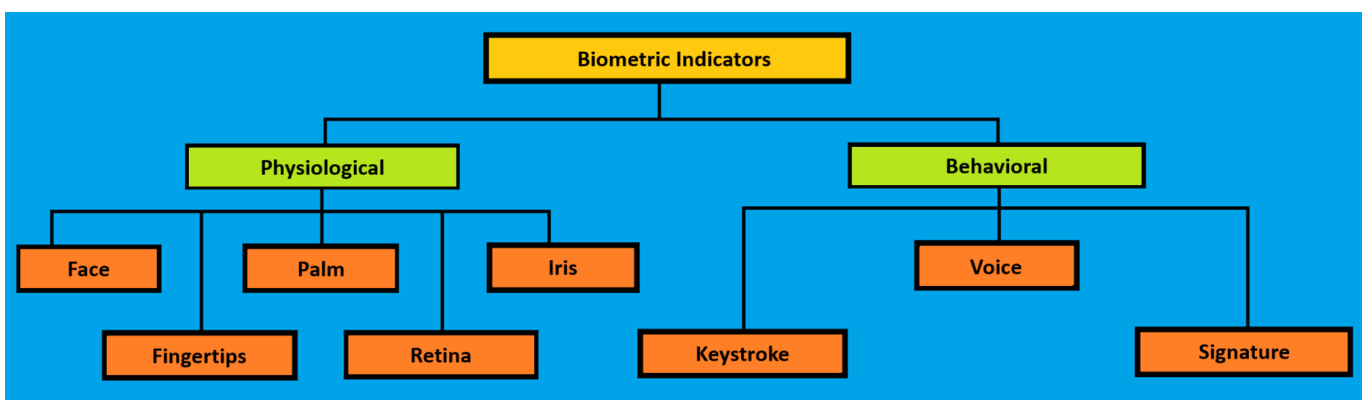

\section{FIGURE 3: Biometric sub-types}

Classification is based on physiological and behavioral traits [14-15]

In addition to the facial recognition and fingerprinting technology, extensive research has been conducted on other biometric recognition techniques, namely, iris/retinal scanning, hand geometry and palm prints, DNA fingerprinting, voice recognition, signature scanning, gait patterns, and keystroke patterns [14-17]. Future endeavors will involve the exploration of other 
anatomical organs and parts, with the potential for I\&A to fulfill essential biometric features (Table 4). These domains include, but are not limited to, finger-vein patterns [15], foot-printing [18], dorsal finger pattern [19], lip-printing [20], and tongue-printing [21].

Electrocardiography (ECG) has also been evaluated as a tool for biometric identification in recent years [22] using peculiar wave-forms (i.e., the peaks and intervals formed by $\mathrm{P}, \mathrm{Q}, \mathrm{R}, \mathrm{S}$, and $\mathrm{T}$ waves). Based upon the specific temporal and amplitude sequences recorded on these points, a set of signals are generated to form a feature extraction that can be deployed to discern one individual from another [23]. Compared to other modalities, the main advantage of this method lies in the impossibility to self-mutilate one's own cardiac activity. However, the cardiac activity does not remain constant over a person's lifetime due to a pathological process or aging. Consequently, biometric ECG can identify individuals but has limited capacity to verify identity over longer periods.

\section{Radio-frequency Identification Technology}

Radio-frequency identification (RFID) uses radio signals as a medium to transfer I\&A data [24]. A small RFID device, usually a microchip, is incorporated into the desired object and emits radio waves detected by an RFID reader. The object can be a product, animal, or a human being, and given the diverse spectrum of its applicability, RFID technology has already penetrated multiple sectors of healthcare, security agencies, agriculture, and manufacturing industries [24]. These RFID tags accommodate data for purposes that range between storing an identification number to incorporating complex details about a product or a person.

Electronic passports are an extension of RFID technology and contain stored personal biometrics [25]. This allows for border and custom securities at airports to conduct I\&A instantly without scanning an individual's face or fingerprints [26]. The RFID chip is incorporated into the main data-page, providing 16 distinct data groups. The first five data groups essentially store critical information related to I\&A. Table 5 presents components of an RFID chip inserted in an e-passport. Note that data groups 2-4 specifically stores the biometric data of that individual [26]. 


\section{Cureus}

$\begin{array}{ll}\text { Data Group } & \text { Details of Stored Information } \\ \text { DG1 } & \text { Document Details } \\ \text { DG2 } & \text { Encoded face } \\ \text { DG3 } & \text { Encoded fingerprints } \\ \text { DG4 } & \text { Encoded iris } \\ \text { DG5 } & \text { Displayed portrait } \\ \text { DG6 } & \text { Reserved for future use } \\ \text { DG7 } & \text { Displayed signatures or usual mark } \\ \text { DG8, DG9, \& DG10 } & \text { Data features } \\ \text { DG11, DG12, \& DG13 } & \text { Additional personal and document details } \\ \text { DG14 } & \text { Reserved for future use } \\ \text { DG15 } & \text { Active authentication public key } \\ \text { DG16 } & \text { Person(s) to notify } \\ \text { SDE } & \text { Security data elements }\end{array}$

\section{TABLE 5: Data groups of an e-passport}

DG, data group [26]

Another similar application is the insertion of an RFID implant into a person's body. These microchip implants are also instrumental in medical settings, especially for patients suffering from a life-threatening medical condition, dementia, communicative disorder or for patients with debilitating psychiatric diseases [27]. Unlike RFID-integrated documents (e.g., e-passport or a smartcard), RFID implants cannot be lost or forgotten. However, implants carry certain privacy and security risks because malicious agencies using compatible RFID readers could access, block or even alter sensitive biometric data stored in the implant [27]. Consequently, the integration of cryptographic features can resolve this issue to some extent by providing encryption on the database. Nevertheless, the RFID implant technology use raises concerns that have yet to be resolved, related to intrinsic technical issues, privacy, ethical concerns, and health-related problems [27-29]. In the field of biometrics, RFID technology is still evolving and will likely offer practical solutions in the future.

\section{Conclusions}

Adermatoglyphia, especially due to acquired causes, is more common than anticipated and is not an uncommon finding in the geriatric population and manual laborers. Despite its utterly benign nature, the relentless invasion of biometric I\&A into modern life via fingerprint verification creates enormous hurdles for patients with irreversible adermatoglyphia. While advancements in biometric technology have rendered the process more rigorous and quicker, these systems are frequently deployed in various institutions and departments without a 
substitute or default alternative option that could function as a solution for patients with absent fingerprints. Therefore, specific guidelines or a substitute I\&A system is recommended that can function globally, as a default program, facilitating I\&A for patients suffering from irreversible adermatoglyphia.

\section{Additional Information \\ Disclosures}

Conflicts of interest: In compliance with the ICMJE uniform disclosure form, all authors declare the following: Payment/services info: All authors have declared that no financial support was received from any organization for the submitted work. Financial relationships: All authors have declared that they have no financial relationships at present or within the previous three years with any organizations that might have an interest in the submitted work. Other relationships: All authors have declared that there are no other relationships or activities that could appear to have influenced the submitted work.

\section{References}

1. Galton F: Fingerprints. Macmillan \& Co, New York; 1892.

2. Cummins H, Midlo C: Palmar and planter epidermal configuration (dermatoglyphics) in European, Americans. Am J Phy Anthropol. 1926, 9:471-502. 10.1002/ajpa.1330090422

3. Bhat GM, Mukhdoomi MA, Shah BA, Ittoo MS: Dermatoglyphics: in health and disease - a review. Int J Res Med Sci. 2014, 2:31-37. 10.5455/2320-6012.ijrms20140207

4. Plateaux A, Lacharme P, Rosenberger C, Jøsang A: One-Time Biometrics for Online Banking and Electronic Payment Authentication. Availability, Reliability, and Security in Information Systems. CD-ARES 2014. Lecture Notes in Computer Science. Teufel S, Min TA, You I, Weippl E (ed): Springer, 2014. 8708:179-193. 10.1007/978-3-319-10975-6_14

5. Ramam M, Krishna SG: A novel cause of economic loss due to hand dermatitis . Arch Dermatol. 2011, 147:753. 10.1001/archdermatol.2011.160

6. Burger B, Fuchs D, Sprecher E, Itin P: The immigration delay disease: adermatoglyphiainherited absence of epidermal ridges. J Am Acad Dermatol. 2011, 64:974-980. 10.1016/j.jaad.2009.11.013

7. Haber R, Helou J, Korkomaz J, Habre M, Ghanem A, Tomb R: Absence of fingertips with focus on dermatological etiologies: national survey and review. J Clin Dermatol. 2015, 3:21-26.

8. Luna PC, Larralde M: Profuse congenital familial milia with absent dermatoglyphics (Basan's Syndrome): description of a new family. Pediatr Dermatol. 2012, 29:527-9. 10.1111/j.15251470.2011.01473.x

9. David TJ: Ridges-off-the-end syndrome in two families, and a third family with a new syndrome. Hum Hered. 1973, 23:42-45. 10.1159/000152550

10. Sergeant A, McPhee N, Holme SA: Acquired loss of fingerprints: do topical corticosteroids play an aetiological role?. Clin Exp Dermatol. 2012, 37:679-680. 10.1111/j.1365-2230.2011.04307.x

11. Cohen PR: Capecitabine-associated loss of fingerprints: report of capecitabine induced adermatoglyphia in two women with breast cancer and review of acquired dermatoglyphic absence in oncology patients treated with capecitabine. Cureus. 2017, 9-1. 10.7759/cureus.969

12. Shen W, Tan T: Automated biometrics-based personal identification . Proc Natl Acad Sci USA. 1999, 28:11065-6. 10.1073/pnas.96.20.11065

13. Sim T, Zhang S, Janakiraman R, Kumar S: Continuous verification using multimodal biometrics. IEEE Trans Pattern Anal Mach Intell. 2007, 29:687-700. 10.1109/tpami.2007.1010

14. Kalyani CH: Various biometric authentication techniques: a review. J Biom Biostat. 2017, 8:371. 10.4172/2155-6180.1000371

15. Yang W, Wang S, Hu J, Zheng G, Chaudhry J, Adi E, Valli C: Securing mobile healthcare data: a smart card based cancelable finger-vein bio-cryptosystem. IEEE Access. 2018, 6:36939-36947. 10.1109/access.2018.2844182

16. Pato JN, Millett LI (ed): Biometric Recognition: Challenges and Opportunities . The National Academies Press, Washington, DC; 2010. 10.17226/12720

17. Hollien H: An approach to speaker identification. J Forensic Sci. 2016, 61:334-344. 
18. Uhl A, Wild P: Footprint-based biometric verification. J Electron Imaging. 2008, 17:011016. 10.1117/1.2892674

19. Chattopadhyay S, Sukul B: Identification from dorsal finger pattern: a new approach . Med Sci Law. 2011, 52:17-21. 10.1258/msl.2011.010145

20. Herrera LM, Fernandes CM da S, Serra M da C: Evaluation of lip prints on different supports using a batch image processing algorithm and image superimposition. J Forensic Sci. 2011, 63:122-129. 10.1111/1556-4029.13507

21. Radhika T, Jeddy N, Nithya S: Tongue prints: a novel biometric and potential forensic tool . J Forensic Dent Sci. 2016, 8:117-9. 10.4103/0975-1475.195119

22. Sellami A, Zouaghi A, Daamouche A: ECG as a biometric for individual's identification . 5th International Conference on Electrical Engineering - Boumerdes / IEEE. 2017, 10.1109/iceeb.2017.8192201

23. Patro KK, Kumar PR: Effective feature extraction of ECG for biometric application. Procedia Comput Sci. 2017, 115:296-306. 10.1016/j.procs.2017.09.138

24. Parkash D, Kundu T, Kaur P: The RFID technology and its applications: A review . Int J Electronics. 2012, 2:109-120.

25. Atanasiu A, Mihailescu MI: Biometric passports (ePassports). 8th International Conference on Communications/IEEE Xplore. 2010, 10.1109/ICCOMM.2010.5509095

26. Malčík D, Drahanský M: Anatomy of biometric passports. J Biomed Biotechnol. 2012, 1-8. $10.1155 / 2012 / 490362$

27. Rotter P, Daskala B, Compano R: RFID implants: opportunities and challenges for identifying people. IEEE Technology and Society Magazine. 2008, 27:24-32. 10.1109/mts.2008.924862

28. Michael K, Michael MG, Ip R: Microchip implants for humans as unique identifiers: a case study on VeriChip. 2008,

29. Michael K, Michael MG: The future prospects of embedded microchips in humans as unique identifiers: the risks versus the rewards. Media Cult Soc. 2013, 35:78-86. 